\section{BMJ Open Respiratory Research}

\title{
First patient-centred set of outcomes for pulmonary sarcoidosis: a multicentre initiative
}

Nynke A Kampstra, ${ }^{\oplus 1,2}$ Jan C Grutters, ${ }^{3,4}$ Frouke T van Beek, ${ }^{4}$ Daniel A Culver, ${ }^{5}$ Robert P Baughman, ${ }^{6}$ Elisabetta A Renzoni, ${ }^{7}$ Wim Wuyts, ${ }^{8}$ Vaslis Kouranos, ${ }^{9}$ Marlies S Wijsenbeek, ${ }^{10}$ Douwe H Biesma, ${ }^{1,11}$ Philip J van der Wees, ${ }^{2}$ Paul B van der $\mathrm{Nat}^{1,2}$

\section{ABSTRACT}

To cite: Kampstra NA Grutters JC, van Beek FT, et al. First patient-centred set of outcomes for pulmonary sarcoidosis: a multicentre initiative. BMJ Open Resp Res 2019;6:e000394. doi:10.1136/ bmjresp-2018-000394

- Additional material is published online only. To view please visit the journal online (http://dx.doi.org/10.1136/ bmjresp-2018-000394).

Received 14 December 2018 Revised 24 January 2019
Check for updates

\section{(C) Author(s) (or their} employer(s)) 2019. Re-use permitted under CC BY-NC. No commercial re-use. See rights and permissions. Published by BMJ.

For numbered affiliations see end of article.

\section{Correspondence to} Nynke A Kampstra; nynkekampstra@gmail.com
Introduction Routine and international comparison of clinical outcomes enabling identification of best practices for patients with pulmonary sarcoidosis is lacking. The aim of this study was to develop a standard set of outcome measures for pulmonary sarcoidosis, using the valuebased healthcare principles.

Methods Six expert clinics for interstitial lung diseases in four countries participated in a consensus-driven RANDmodified Delphi study. A mixed-method approach was applied for the identification of an outcome measures set and initial conditions for patients with pulmonary sarcoidosis. The expert team consisted of multidisciplinary professionals $(n=14)$ from Cleveland Clinic, Cincinnati MC, Erasmus MC, Leuven UZ, Royal Brompton and St. Antonius Hospital. During a ranking process, participants were instructed to rank variables on a scale from 1 to 10 based on whether it has (1) impact of the outcome on quality of life, (2) impact of quality of care on the outcome and (3) the number of patients negatively affected by the outcome. Results An outcome measures set was defined consisting of seven outcome measures: mortality, pulmonary function, soluble interleukin-2 receptor change as an activity biomarker, weight gain, quality of life, osteoporosis and clinical outcome status.

Discussion Collecting outcomes in pulmonary sarcoidosis internationally and the use of a broadly accepted set can enable international comparison. Differences in outcomes can potentially be used as a starting point for quality improvement initiatives.

\section{INTRODUCTION}

Sarcoidosis is a chronic systemic disease of unknown aetiology, characterised histologically by granulomatous inflammation. Existing treatment options include either no medication or a mix of first-line, secondline and third-line medication with trade-offs between treating inflammation and quality of life (QoL). ${ }^{1}$ A chronic disease course requires long-term treatment with corticosteroids, cytotoxics and other agents that can have a serious impact on the quality of life. ${ }^{2}$ Significant grey areas exist in approaches

\section{Key messages}

- This study provides detailed information on how the first set of patient-centred outcomes in patients with a diagnosis of pulmonary sarcoidosis was developed.

- The international process resulted in a consensus-driven recommended set.

- This standard setallows meaningful comparisons of outcomes and practices at different hospitals which can enable sharing of 'best practices' to improve the care for pulmonary sarcoidosis globally.

to treatment and thus how care is delivered across different countries and centres. ${ }^{3}$ Little knowledge is available regarding outcomes of delivered care in relation to the various treatment options. Therefore, there is a need for standardisation of core outcomes to ensure high-value care delivery for all patients with sarcoidosis globally.

Patients suffering from chronic diseases have persistent needs and therefore need ongoing healthcare. Accordingly, patients with complex chronic conditions, such as sarcoidosis, are also the costliest patients, and costs increase with the number of chronic conditions. ${ }^{4}$ In patients with sarcoidosis, it has been confirmed they have higher rates of comorbidity and complexity compared with a matched control group (matched for age and gender). Furthermore, it was found that the main comorbidities were pulmonary, liver, autoimmune and neoplastic disease in patients with sarcoidosis compared with controls. ${ }^{5}$ It was estimated that commercial payers incurred US\$19 714 annually on healthcare costs spent per patient with sarcoidosis in the USA, with outpatient visits and inpatient admissions as the two main cost drivers. ${ }^{6}$ 
Globally, healthcare providers are driven by similar goals: to improve patient experiences and healthcare outcomes, to become more efficient and to reduce the costs as well as to innovate the way care is provided. As addressed by Porter, value-based healthcare (VBHC) could be a guiding principle in achieving these multiple goals. ${ }^{78}$ In particular, transparently sharing treatment outcomes of routine clinical care can help hospitals to learn from each other and improve patient value, defined as outcomes over costs.

Sarcoidosis often affects young and middle-aged adults. Patients suffer from a broad range of non-specific symptoms, with high variability in the degree of inflammation as well as organs affected. In more than $90 \%$ of the cases, sarcoidosis affects the lungs. ${ }^{2-11}$ Spontaneous remissions occur in approximately two-thirds of the patients, but the disease course is chronic in $10 \%-30 \%$ of the patients. ${ }^{9}$ Incidence and prevalence rates reported in the literature are highly variable. The prevalence varies over geographical regions as well as ethnic groups, with the highest sarcoidosis prevalence reported in the Nordic countries and in individuals of African descent. ${ }^{912}$ For this study, we aimed to specifically develop a standard set of outcome measures for patients with pulmonary sarcoidosis.

In order to optimise treatment to the individual patient with sarcoidosis, the availability of centre-level outcome data has the potential to provide important advantages for quality improvement efforts. Hospitals can learn from variations in the outcomes of care, as demonstrated in cystic fibrosis centres. ${ }^{13}$ Globally, there is a broader interest in studying the within-hospital as well as the between-hospital variation in various medical conditions. ${ }^{1415}$ Without having defined a set of meaningful and internationally accepted measures, it is not possible to compare results and identify best practices.

The primary objective of this study was to define a consensus-driven, patient-centred outcome set enabling international comparison of clinical outcomes of patients with pulmonary sarcoidosis, including a set of initial conditions needed for case-mix corrections.

\section{METHODS}

\section{Study structure and design}

A project group supervised the selection process of the outcome set. Initial identification of potentially relevant outcomes was established by an international working group with pulmonologists from six recognised expert clinics in four countries: Cleveland Clinic (USA), Cincinnati MC (USA), Erasmus MC (the Netherlands), Leuven UZ (Belgium), the Royal Brompton (UK) and the St. Antonius Hospital (the Netherlands).

An international team of experts $(n=14)$ from the six expert clinics convened through webinars and a face-toface session to reach consensus on the set of outcome measures and case-mix variables using a structured consensus-driven RAND-modified Delphi method (see online supplementary material appendix 1 for the full list of experts). ${ }^{16} 17$ The selection process was conducted between January 2014 and January 2015.

\section{Patient population and condition scope}

The outcome set was designed for patients with pulmonary sarcoidosis. The working group acknowledged sarcoidosis as a very heterogeneous population, with the possibility of single extrapulmonary organ involvement, such as ocular sarcoidosis. However, as the lungs are involved in $90 \%$ of patients with sarcoidosis, ${ }^{2} 18$ only patients with pulmonary involvement (including isolated hilar/mediastinal) were included in the dataset. The definition for sarcoidosis for this patient group was in line with the international accepted statement on sarcoidosis ${ }^{9}$ : (1) the patient has to be diagnosed with pulmonary sarcoidosis and (2) the diagnosis is performed by a pulmonologist.

\section{Development of the standard set}

In order to develop the standard set, a systematic approach was employed, identifying outcomes based on the three-tier principles of Porter: tier 1, health status (survival and degree of health); tier 2, recovery process (time to recovery, disutility of care); and tier 3, sustainability of health (ie, sustainability of health or recovery and long-term consequences of therapy). ${ }^{8}$

The development of the set was structured in three main phases. First, as introduced by Kaplan and Porter, ${ }^{819}$ the care delivery value chain for pulmonary sarcoidosis was described. This allowed to map the total care delivery of the diverse activities. Second, a literature review was carried out by the working group guiding the identification of important outcomes and the related initial conditions. Third, the working group identified potential outcomes, applying the process for standard set development introduced by Meetbaar Beter (in 2017, Meetbaar Beter merged with the Netherlands Heart Registry). ${ }^{20} 21$ The process described by Meetbaar Beter consists of the following steps: a list of the most important outcomes was sent to the expert group and prioritised. A structured consensus-driven, RAND-modified Delphi method was employed to prioritise the important outcomes anonymously on a scale from 0 to 10 (not important to most important). The outcomes were ranked on three criteria: (1) impact of the outcome on quality of life, (2) impact of quality of care on the outcome and (3) the number of patients negatively affected by the outcome. Based on the total score prioritising the outcomes, four online webinar discussions and one face-to-face meeting, final consensus on the outcome set was reached. A secondary goal of this process was to define a standard set of initial conditions required for potential case-mix corrections. This was defined based on expert opinion and was ranked accordingly. When differences in prioritisation emerged, they were openly discussed until consensus was reached. 
Table 1 Summary of standard set of outcomes for patients with pulmonary sarcoidosis

\begin{tabular}{|c|c|c|c|c|}
\hline Outcome set & Category & Details & Timing & Data source \\
\hline 1. Mortality & $\begin{array}{l}\text { Longitudinal } \\
\text { outcomes }\end{array}$ & Date of death & $\begin{array}{l}\text { Tracked } \\
\text { throughout }\end{array}$ & Administrative \\
\hline 2. Pulmonary function & Clinical monitoring & $\begin{array}{l}\text { 1. FVC\% predicted and absolute } \\
\text { over treatment period } \\
\text { 2. FEV } \% \text { predicted and absolute } \\
\text { over treatment period } \\
\text { 3. DLCO\% predicted and absolute } \\
\text { over treatment period }\end{array}$ & $\begin{array}{l}\text { Every 3-6 months } \\
\text { (depending } \\
\text { on severity of } \\
\text { sarcoidosis) }\end{array}$ & Clinical \\
\hline
\end{tabular}

\begin{tabular}{|c|c|c|c|c|}
\hline $\begin{array}{l}\text { 3. Soluble interleukin-2 } \\
\text { receptor (sIL-2R) change as } \\
\text { an activity biomarker }\end{array}$ & Clinical monitoring & $\begin{array}{l}\text { 1. Date of measurement } \\
\text { 2. sIL-2R (measured in } \mathrm{pg} / \mathrm{mL} \text {, limit } \\
>3000 \text { ) }\end{array}$ & $\begin{array}{l}\text { Every visit to the } \\
\text { clinic }\end{array}$ & Clinical \\
\hline 4. Weight gain & Clinical monitoring & $\begin{array}{l}\text { Weight }(\mathrm{kg}) \text { measured at each } \\
\text { pulmonary function test }\end{array}$ & $\begin{array}{l}\text { Every visit to the } \\
\text { clinic }\end{array}$ & Clinical \\
\hline $\begin{array}{l}\text { 5. Quality of life; physical } \\
\text { functioning }\end{array}$ & $\begin{array}{l}\text { Patient-reported } \\
\text { health status }\end{array}$ & $\begin{array}{l}\text { King's Sarcoidosis Questionnaire } \\
\text { and the Fatigue Assessment Scale }\end{array}$ & Every 6 months & Patient reported \\
\hline 6. Osteoporosis & Clinical monitoring & $\begin{array}{l}\text { Diagnosis T-score } \\
1=\text { Normal }>-1.0 \\
2=\text { Osteopenia }<-1.0,>-2.5 \\
3=\text { Osteoporosis }<-2.5 \\
4=\text { Severe osteoporosis }<-2.5 \text { plus } \\
\text { fragility fractures } \\
5=\text { Not indicated } \\
\text { Based on } \text { WHO Osteoporosis }^{\text {Classification }}{ }^{52}\end{array}$ & $\begin{array}{l}\text { Monitor throughout } \\
\text { treating the patient }\end{array}$ & Clinical \\
\hline
\end{tabular}

\section{RESULTS}

\section{Pulmonary sarcoidosis standard set}

The care delivery value chain provides a detailed overview of care provided for patients with pulmonary sarcoidosis to guide the initial selection of outcome measures (see online supplementary material appendix 2 for a full description). After identifying the most important outcomes from the care delivery chain, literature and expert opinion, an initial set of 34 outcomes was presented to the expert group (see online supplementary appendix 4). Next, outcome measures were ranked based on the Meetbaar Betercriteria delineated earlier. ${ }^{2021}$ Finally, the ranking and expert opinion discussions resulted in seven outcome measures (table 1) and 10 initial conditions (table 2). Further information how the outcomes were prioritised is presented in the online supplementary material appendix 4 . An overview of data collection and its timeline is presented in figure 1.
In the following paragraphs, we discuss our considerations in selecting the seven outcome measures in relation to the literature. For more detailed information concerning the outcome measures, please see online supplementary appendix 3 in the online supplement.

\section{Tier 1: outcome measures 1, 2 and 3: health status (survival and degree of health)}

Survival at 1 and 5 years after the diagnosis is an important outcome (outcome measure 1), especially for patients with advanced pulmonary sarcoidosis. Survival is measured as all-cause mortality, calculated from clinical and administrative data sources. Sarcoidosis-related mortality is reported to be up to $7.6 \%$ in a US-based population. ${ }^{22}$ Most deaths are due to pulmonary fibrosis, pulmonary hypertension, neurological and cardiac involvement. ${ }^{9}$

Outcome measure 2 is pulmonary function $\left(\mathrm{FVC}, \mathrm{FEV}_{1}\right.$ and $\mathrm{DLCO}_{c}$ ), which is widely used to monitor disease 


\begin{tabular}{|c|c|c|c|}
\hline Timing for collection & Measure & Details & Source \\
\hline $\begin{array}{l}\text { First contact with hospital } \\
\text { services }\end{array}$ & Age & Date of birth & Administrative \\
\hline At time of clinical visit & Body mass index & Weight and height needed & Clinical \\
\hline At time of clinical visit & $\begin{array}{l}\text { Comorbidity ICD-10+sleep } \\
\text { apnoea }\end{array}$ & Documented in history & Clinical \\
\hline $\begin{array}{l}\text { First contact with hospital } \\
\text { services }\end{array}$ & Ethnicity & Documented in history & Administrative \\
\hline $\begin{array}{l}\text { First contact with hospital } \\
\text { services }\end{array}$ & Gender & $\begin{array}{l}\text { Gender at birth } \\
\text { Documented in history }\end{array}$ & Administrative \\
\hline At time of clinical visit & Multiorgan involvement ${ }^{53}$ & $\begin{array}{l}\text { Various clinical manifestations for the } \\
\text { probability of various sarcoidosis-related } \\
\text { organ involvement. Ranking options are highly } \\
\text { probable, at least probable, possible or no } \\
\text { consensus }\end{array}$ & Clinical \\
\hline $\begin{array}{l}\text { First contact with hospital } \\
\text { services }\end{array}$ & $\begin{array}{l}\text { Opinion stage (first, } \\
\text { second, third) }\end{array}$ & $\begin{array}{l}\text { 1. First opinion } \\
\text { 2. Second opinion } \\
\text { 3. Third opinion }\end{array}$ & Clinical \\
\hline Stadium X-thorax ${ }^{42}$ & $\begin{array}{l}\text { Scadding stage based on } \\
\text { chest X-ray }\end{array}$ & $\begin{array}{l}\text { 1. Stage 0: normal } \\
\text { 2. Stage I: lymph nodes in hili or mediastinum } \\
\text { 3. Stage II and III: I plus distortion in lung (II) } \\
\text { 4. Stage IV: fibrosis in lung, significant fibrotic } \\
\text { lesions/end-stage disease }\end{array}$ & $\begin{array}{l}\text { Clinician evaluation/ } \\
\text { administrative }\end{array}$ \\
\hline $\begin{array}{l}\text { First contact with hospital } \\
\text { services }\end{array}$ & Smoking history & $\begin{array}{l}\text { 1. Never } \\
\text { 2. Ever } \\
\text { 3. Active (moment of diagnosis an active } \\
\text { smoker) }\end{array}$ & Administrative \\
\hline $\begin{array}{l}\text { First contact with hospital } \\
\text { services }\end{array}$ & Socioeconomic status & Postal code & Administrative \\
\hline
\end{tabular}

progression. Currently, serial FVC is considered as the best endpoint to monitor during the course of care for pulmonary sarcoidosis. ${ }^{23}$
Finally, soluble interleukin-2 receptor (sIL-2R) was selected as outcome measure 3. SIL-2R is considered to be a marker of T-cell activation. ${ }^{24} \mathrm{~A}$ shortcoming of

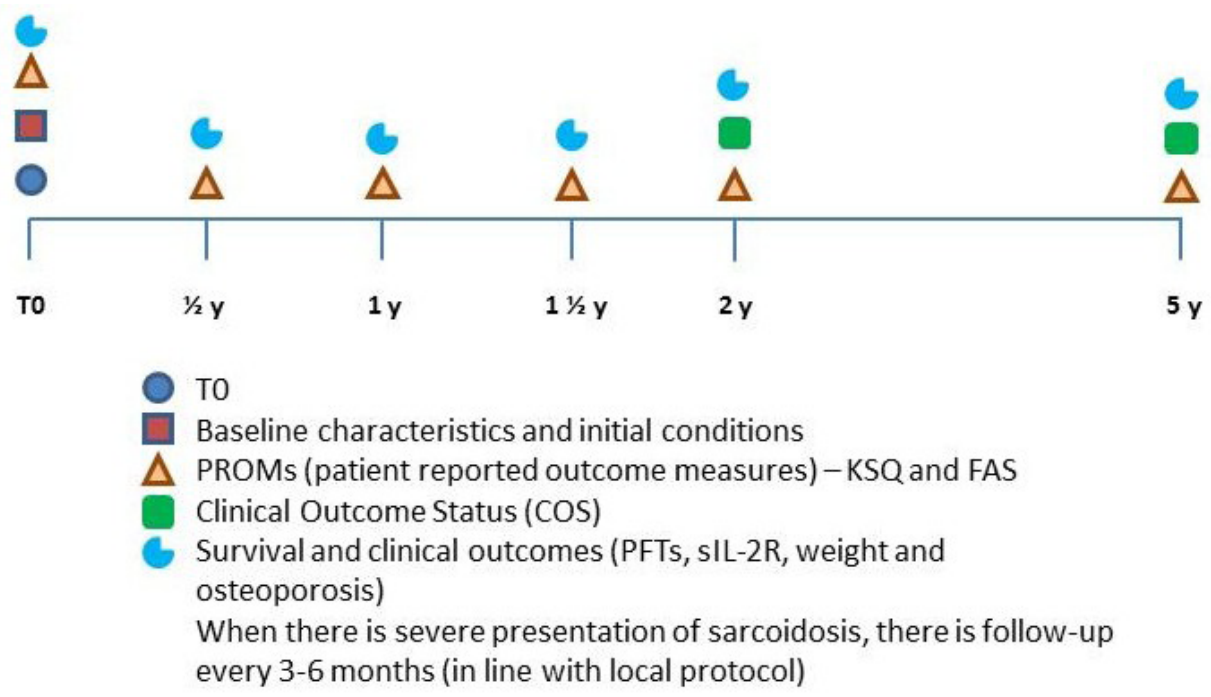

Figure 1 Example of a timeline when outcomes and baseline factors should be collected for patients with pulmonary sarcoidosis. This timeline represents the outcome data collection points for a possible treatment path of a patient with pulmonary sarcoidosis. It does not advocate a particular treatment or treatment combination. Patients can receive follow-up for up to 5 years, but this can also be longer depending on the disease severity and whether the patient experiences chronic pulmonary sarcoidosis. T0=at first physician visit. FAS, Fatigue Assessment Scale; KSQ, King's Sarcoidosis Questionnaire. 
this outcome is the fact that it is not routinely measured and implemented in all the collaborating expert clinics. Furthermore, there are conflicting data regarding the correlation between sIL-2R level changes and respective treatment response. ${ }^{25}$ However, it outperforms conventional biomarkers such as $\mathrm{ACE}^{26}$ and is cheaper and more widely available than sensitive tests like fluorodeoxyglucose PET. $^{27}$

\section{Tier 2: outcome measure 4: recovery process (time to} recovery, disutility of care)

The treatment of pulmonary sarcoidosis aims at preventing a progressive disease pattern with organ failure. The clinical manifestations are widely variable, ranging from asymptomatic radiographic findings to a more chronic progressive disease pattern with multiple organ failure. ${ }^{28}$ However, complications due to the treatment of pulmonary sarcoidosis are also significant, such as adverse side effects due to high-dose and/or long-term prednisone use, excessive weight gain, risk of osteoporosis and fatigue. ${ }^{29-31}$ Globally, corticosteroids, such as prednisone, remain the mainstay of therapy in sarcoidosis. ${ }^{9} 32$ The initial recommended dose of prednisone is 20-40 $\mathrm{mg}$ /day, which should later be tapered down to a dose around or below the $10 \mathrm{mg} /$ day ${ }^{33}$ However, it remains debated whether prednisone therapy modifies long-term progression of the disease. ${ }^{34}$ We chose weight gain as a measure of disutility of care, outcome measure 4 in the outcome measures set.

\section{Tier 3: outcome measures 5, 6 and 7: sustainability of health} (ie, sustainability of health of or recovery and long-term consequences of therapy)

Health-related quality of life (HRQOL), a key measure for patients with pulmonary sarcoidosis, is outcome measure 5. Fatigue is the most common complaint in patients with pulmonary sarcoidosis, reported by $50 \%$ to $80 \%$ of patients. ${ }^{35}{ }^{36}$ The process aims to select well-validated instruments to address the multidimensional outcome domains, minimising the burden for the patients (eg, number of questionnaires/questions to fill out) on the one hand, while maximising the likelihood of solid longitudinal data collection on the other hand. The Fatigue Assessment Scale (FAS) and King's Sarcoidosis Questionnaire (KSQ) were selected as the most appropriate patient-reported outcome measures in order to monitor changes in patients' quality of life (online supplementary material appendix 5 and appendix 6). The FAS is a well-defined and validated questionnaire in patients with sarcoidosis. ${ }^{23} 37$ The cut-off score for presence of fatigue is $>21$ points. ${ }^{23}$ The minimal clinical important difference is defined at a $10 \%$ reduction or a change of four points. ${ }^{38}$ The KSQ is a self-administered measure for sarcoidosis covering five different domains of health status: (1) general health status, (2) lung, (3) medication, (4) skin and (5) eyes. ${ }^{39}$ It consist of 29 questions. The KSQ is available in multiple languages. ${ }^{39} 40$
Patients with pulmonary sarcoidosis are at risk for developing osteoporosis for a number of reasons, including corticosteroid treatment and reduced mobility secondary to lung function impairment/musculoskeletal issues or other internal organ involvement such as the heart. Data on osteoporosis development were therefore included as outcome measure 6 of the set.

The WASOG Task Force recommends to score patients based on nine predefined criteria, 2 and/or 5 years after diagnosis, introduced as the clinical outcome status (COS) ${ }^{41}$ The COS is defined as outcome measure 7 of the set. The aim of applying the COS is to standardise the clinical outcome description of patients with sarcoidosis and can be seen as an important tool for treatment related classification. For example, patients with persistent disease still on therapy at time of repeat evaluation are $\operatorname{COS} 7,8$ or 9 .

\section{Initial conditions}

A minimum set of initial conditions to control outcomes for differences in patient characteristics was defined. This includes characteristics of pulmonary classification on a chest radiograph into five stages (Scadding stage). ${ }^{42}$ Also, general patient demographics (age, sex, first, secondopinion or third-opinion stage, race/ethnicity, body mass index, comorbidities) and treatment-related factors are included. These initial conditions are associated with the disease outcomes (table 2).

The included comorbidities are based on the ICD-10 codes plus the addition of sleep apnoea (online supplementary appendix 3). This was determined by the treating physician and entered into the patient's medical record. For pulmonary sarcoidosis, the ability to identify black/African-American patients is important, as the disease was found to be more severe in black patients. ${ }^{43}$ Race/ethnicity documentation however differs by country, as well as the means to capture the information (self-reported; Caucasian or non-Caucasian vs Hispanic or non-Hispanic). For more detailed information concerning the initial conditions, please see online supplementary appendix 3 . The initial conditions were extracted from the patient's administrative and clinical data (such as Scadding stage, history of diabetes mellitus or sleep apnoea) and were collected when the patient visits the clinic for the first time (table 2).

\section{Medication use}

In addition to the outcome set and the case-mix variables, we also decided to collect information concerning the patients' medication at diagnosis and at the time of each visit to the clinic. We aimed to identify the duration and variation of first-line, second-line and third-line therapy and to allow comparison between centres. In addition, in relation to weight changes, the team of experts thought medication differences could provide meaningful information to better explain weight changes due to prednisone use. Corticosteroid therapy have been reported to lead to significant changes in HRQOL. ${ }^{44}$ Even low 
doses of prednisone have been associated with significant morbidity. ${ }^{30} 31$ Although this was not part of the outcome measures set, consensus was reached to monitor the following drugs: corticosteroids, methotrexate, azathioprine, non-steroidal anti-inflammatory drugs, infliximab, adalimumab, other anti-TNF, leflunomide, inhalation therapy, other systematic therapy for (extra)pulmonary sarcoidosis and hydroxychloroquine.

\section{DISCUSSION}

A first outcome measure set was developed for patients with pulmonary sarcoidosis consisting of seven outcome measures: mortality ( 1 and 5 years), pulmonary function $\left(\mathrm{FEV}_{1}, \mathrm{FVC}, \mathrm{DLCO}_{\mathrm{c}}\right)$, sIL-2R change as an activity biomarker, weight gain, quality of life, osteoporosis and clinical outcome status. Routine data collection based on standardised outcome measures creates an opportunity to improve patient care. A reliable data collection process for patients with pulmonary sarcoidosis enables us to compare outcomes between various clinics/treatments, which can ultimately help to identify best practices.

The international consensus process resulted in a set of patient-centred outcomes with case-mix variables. This can enable clinicians to measure and benchmark outcomes. It is, however, important to note that the set presented in our paper should not limit any inclusion of additional treatment and/or process-related outcomes supporting quality improvement efforts. It is expected that in efforts to create a multicentre registry, centres will continue to collect additional data, such as the initial dose of prednisone, the rate of prednisone tapering and the timing of a potential switch to second-line therapy (such as methotrexate or azathioprine).

This outcome measures set could be used on a monthly or yearly basis in order to benchmark outcomes. Moreover, this set can be used to compare the quality of care delivered by different centres around the world, which in turn can trigger discussion and define future learning potential for other clinics treating this patient group. Second, it could be used to assess best practices in a field where there is a scarcity on evidence-based therapies. Other initiatives have developed classification protocols, although this is more based on clinical criteria as a tool for studies evaluating disease mechanisms in patients with sarcoidosis to be correlated with clinical outcomes. ${ }^{45}$ For example, the GRADS initiative aims to compare blood genomics with clinical phenotypic variables and assess each participant's clinical course during follow-up. ${ }^{46}$ This recommended outcome measures set is a first step at applying a global standard. Future experiences in comparing outcomes using the set are needed to further refine the global standard set.

Ultimately, healthcare-related patient value should be defined as value achieved from the perspective of the patient and their respective changes in most important clinical outcomes relative to its costs. ${ }^{8}$ This includes perceived health status, QoL as well the impact of choices made during treatment, for example, weight gain as a side effect due to prednisone. The establishment of an international global standard to collect and compare outcomes for patients with pulmonary sarcoidosis will enable more systematic follow-up of the patients' quality of life.

In order to support further progress to measure and transparently compare outcomes for pulmonary sarcoidosis, investments should be made in a longitudinal-oriented registry. This will result in a more structured process when collecting this type of outcome data. In addition, improving the data infrastructure and relying on less manual data entry can improve the validity of the data.

The ultimate goal when reporting clinical outcomes is to inform patients, clinicians and managers with credible performance data. ${ }^{47}$ Additionally, improved documentation, open communication, encouraging quality improvement and increasing informed decision-making for patients are of great importance when reporting and comparing outcomes. ${ }^{48}$ Making use of a clinical registry and reporting outcome data through, for example, annual reports to the public can promote quality improvements in healthcare, reduce potential variations in the quality of care delivered and improve data validity. ${ }^{49} 50$

The set was developed by physicians, as there was a strong need for standardisation from the medical specialties. Annual maintenance cycles in order to evaluate the set should be considered important to continuously improve the set, as suggested by others. ${ }^{21}$ These cycles can be used to generate new scientific input to re-evaluate the outcome measures incorporated in the set.

The interdisciplinary character can be improved (eg, include radiologist and psychologist in the expert group during maintenance cycles). Also, five out of the 14 expert group members were affiliated with the St. Antonius Hospital. This was due to the fact that this centre initiated the study. Although this can create potential bias, during the webinars consensus was reached among all expert group members. In addition, it is necessary to discuss and validate the set with patients and possibly further improve the set using their perspectives as we did not include patient perspectives in the generation of the consensus. In a recent study (in press), survey findings showed that patients $(n=1842)$ want quality of life and functionality to be included as outcomes in their treatment. $^{51}$ In this study, patients from different counties were included (692 Dutch, 528 German, 338 English, 148 Italian, 107 Spanish, 29 French). Finally, for the development of this set, we had an international group with experts from different centres, but not all continents were represented. Future efforts on updating the outcome set should put more efforts on a larger global coverage and collaboration between different centres treating patients with pulmonary sarcoidosis. 


\section{CONCLUSIONS}

The international process resulted in a consensus-driven recommended first set of patient-centred outcomes in patients with a diagnosis of pulmonary sarcoidosis. Applying this outcome set has the potential to better inform patients, healthcare providers and other stakeholders in achieving value-based care for patients with pulmonary sarcoidosis. The full potential of applying VBHC principles in pulmonary sarcoidosis is however yet to be explored.

\section{Author affiliations}

1 Department of Value-Based Healthcare, St. Antonius Hospital, Nieuwegein, The Netherlands

${ }^{2}$ Radboud Institute for Health Sciences, Scientific Center for Quality of Healthcare (IQ Healthcare), Radboud University Medical Center, Nijmegen, The Netherlands

${ }^{3}$ Division of Heart and Lungs, University Medical Centre Utrecht, Utrecht, The Netherlands

${ }^{4}$ Interstitial Lung Diseases Center of Excellence, Department of Pulmonology, St. Antonius Hospital, Utrecht, The Netherlands

${ }^{5}$ Department of Pulmonary Medicine, Cleveland Clinic, Cleveland, Ohio, USA ${ }^{6}$ Department of Medicine, University of Cincinnati Medical Center, Cincinnati, Ohio, USA

${ }^{7}$ Interstitial Lung Disease Unit, Royal Brompton Hospital, Imperial College, London, UK

${ }^{8}$ Department of Respiratory Medicine, Universitaire Ziekenhuizen Leuven, Leuven, Belgium

${ }^{9}$ Department of Interstitial Lung Disease, Imperial College London-Royal Brompton Campus, London, UK

${ }^{10}$ Department of Pulmonary Medicine, Erasmus MC, Rotterdam, The Netherlands

${ }^{11}$ Department of Internal Medicine, University Medical Centre Utrecht, Utrecht, The Netherlands

Acknowledgements We thank the sarcoidosis patient association (SBN) for the research grant awarded in 2016 for this project. We would like to thank Dr Wim F van den Bosch for his help at the start of this study, who worked as a senior advisor at the quality and safety department at the St. Antonius Hospital (Nieuwegein, the Netherlands). Furthermore, we would like to thank Dr Bernt van den Blink for his helpful input during the start of the study, during which he worked as a pulmonologist at the Erasmus Medical Center (Rotterdam, the Netherlands).

Contributors NAK, JCG, FTB, DAC, RPB, EAR, WW, VK, MSW, DHB, PJvdW and PBvdN (hereinafter referred to as 'all authors') contributed to the conception and design of the study. NAK was the major contributor in writing the manuscript. NAK JCG, PJvdW and PBvdN analysed and interpreted the data. All authors contributed to the interpretation of the results. All authors critically revised the manuscript for important intellectual content. All authors read and approved the final manuscript.

Funding This work was supported by The Netherlands Organisation for Health Research and Development (ZonMw) under project number 842001005 .

Disclaimer The funders had no role in the study design, data collection, analysis and decision in where to publish the manuscript.

Competing interests RB reports grants and personal fees from Mallinckrodt, grants and personal fees from Genentech, grants from Bayer, grants from Gilead, grants from Astra Zeneca, grants from Novartis, outside the submitted work. DC reports non-financial support from Gilead, grants and other from Mallinkrodt, nonfinancial support from Araim, outside the submitted work. EAR reports personal fees from Roche, personal fees from Boehringer Ingelheim, outside the submitted work. JCG reports grants from ZonMw, during the conduct of the study. WW reports grants from Roche, grants from Boehringer Ingelheim payed to his institution, outside the submitted work.

Patient consent for publication Not required.

Provenance and peer review Not commissioned; externally peer reviewed.

Data sharing statement № additional data are available.

Open access This is an open access article distributed in accordance with the Creative Commons Attribution Non Commercial (CC BY-NC 4.0) license, which permits others to distribute, remix, adapt, build upon this work non-commercially, and license their derivative works on different terms, provided the original work is properly cited, appropriate credit is given, any changes made indicated, and the use is non-commercial. See: http://creativecommons.org/licenses/by-nc/4.0/.

\section{REFERENCES}

1. Wijsenbeek MS, Culver DA. Treatment of sarcoidosis. Clin Chest Med 2015;36:751-67.

2. Iannuzzi MC, Fontana JR. Sarcoidosis: clinical presentation, immunopathogenesis, and therapeutics. JAMA 2011;305:391-9.

3. Valeyre D, Prasse A, Nunes $\mathrm{H}$, et al. Sarcoidosis. Lancet 2014;383:1155-67.

4. Gerteis J, Izrael D, Deitz D, et al. Multiple chronic conditions chartbook. Rockville MD: Agency for Healthcare Research and Quality, 2014

5. Brito-Zerón P, Acar-Denizli N, Sisó-Almirall A et al. The burden of comorbidity and complexity in sarcoidosis: impact of associated chronic diseases. Lung 2018;196:239-48.

6. Rice JB, White A, Lopez A, et al. High-cost sarcoidosis patients in the United States: patient characteristics and patterns of health care resource utilization. J Manag Care Spec Pharm 2017;23:1261-9.

7. Porter ME, Larsson S, Lee TH. Standardizing patient outcomes measurement. N Engl J Med Overseas Ed 2016;374:504-6.

8. Porter ME. What is value in health care? N Engl $\mathrm{J}$ Med 2010;363:2477-81.

9. Hunninghake GW, Costabel U, Ando M, et al. Statement on sarcoidosis (the joint statement of the American Thoracic Society, the European Respiratory Society, and the World Association of Sarcoidosis and Other Granulomatous Disorders). Am J Respir Crit Care Med 1999;160:736-55.

10. Baughman RP, Lower EE, Gibson K. Pulmonary manifestations of sarcoidosis. La Presse Médicale 2012;41:e289-302.

11. Drent M, Lower EE, De Vries J. Sarcoidosis-associated fatigue. Eur Respir J 2012;40:255-63.

12. Milman N, Selroos O. Pulmonary sarcoidosis in the Nordic countries 1950-1982. II. Course and prognosis. Sarcoidosis 1990;7:113-8.

13. Kraynack NC, McBride JT. Improving care at cystic fibrosis centers through quality improvement. Semin Respir Crit Care Med 2009;30:547-58.

14. McNamara RL, Spatz ES, Kelley TA, et al. Standardized outcome measurement for patients with coronary artery disease: consensus from the International Consortium for Health Outcomes Measurement (ICHOM). J Am Heart Assoc 2015;4. doi:10.1161/ JAHA. 115.001767

15. Morgans AK, van Bommel AC, Stowell C, et al. Development of a standardized set of patient-centered outcomes for advanced prostate cancer: an international effort for a unified approach. Eur Urol 2015;68:891-8.

16. Grol R, Baker R, Moss F. Quality improvement research: understanding the science of change in health care. Qual Saf Health Care 2002:11:110-1.

17. Fitch K, Bernstein SJ, Aguilar MD, et al. The RAND/UCLA appropriateness method user's manual. RAND, 2001.

18. Baughman RP, Drent M, Culver DA, et al. Endpoints for clinical trials of sarcoidosis. Sarcoidosis Vasc Diffuse Lung Dis 2012;29:90-8

19. Kaplan RS, Porter ME. The big IDEA-how to solve the cost crisis in health care. Harv Bus Rev 2012;46.

20. Meetbaar Beter. Meetbaar Beter Boeken, 2013. Available: http:// www.meetbaarbeter.com/documents/meetbaar-beter-boeken/ boeken-2013/ [Accessed 11 Dec 2017].

21. Daeter EJ, Timmermans MJC, Hirsch A, et al. Defining and measuring a standard set of outcomes in coronary artery disease. Am J Cardiol 2018;121:1477-88.

22. Swigris JJ, Olson AL, Huie TJ, et al. Sarcoidosis-related mortality in the United States from 1988 to 2007. Am J Respir Crit Care Med 2011;183:1524-30.

23. Baughman RP, Drent M, Culver DA, et al. Endpoints for clinical trials of sarcoidosis. Sarcoidosis Vasc Diffuse Lung Dis 2013;29:90-8.

24. Semenzato G, Pizzolo G, Zambello R. The interleukin-2/interleukin-2 receptor system: structural, immunological, and clinical features. Int J Clin Lab Res 1992;22:133-42.

25. Chopra A, Kalkanis A, Judson MA. Biomarkers in sarcoidosis. Expert Rev Clin Immunol 2016;12:1191-208.

26. Rothkrantz-Kos S, van Dieijen-Visser MP, Mulder PG, et al. Potential usefulness of inflammatory markers to monitor respiratory functional impairment in sarcoidosis. Clin Chem 2003:49:1510-7.

27. Keijsers RG, Grutters JC, Thomeer M, et al. Imaging the inflammatory activity of sarcoidosis: sensitivity and inter observer agreement of (67)Ga imaging and (18)F-FDG PET. Q J Nucl Med Mol Imaging 2011;55:66-71. 
28. Judson MA, Thompson BW, Rabin DL, et al. The diagnostic pathway to sarcoidosis*. Chest 2003;123:406-12.

29. de Kleijn WP, De Vries J, Lower EE, et al. Fatigue in sarcoidosis: a systematic review. Curr Opin Pulm Med 2009;15:499-506.

30. Khan NA, Donatelli CV, Tonelli AR, et al. Toxicity risk from glucocorticoids in sarcoidosis patients. Respir Med 2017;132:9-14.

31. Broos CE, Poell LHC, Looman CWN, et al. No evidence found for an association between prednisone dose and FVC change in newlytreated pulmonary sarcoidosis. Respir Med 2018;138S:S31-S37.

32. Schutt AC, Bullington WM, Judson MA. Pharmacotherapy for pulmonary sarcoidosis: a Delphi consensus study. Respir Med 2010;104:717-23.

33. Baughman RP, Costabel U, du Bois RM. Treatment of sarcoidosis. Clin Chest Med 2008:29:533-48.

34. Paramothayan NS, Lasserson TJ, Jones P, et al. Corticosteroids for pulmonary sarcoidosis. Cochrane Database Syst Rev 2005;5(5 Suppl).

35. Michielsen HJ, Drent M, Peros-Golubicic T, et al. Fatigue is associated with quality of life in sarcoidosis patients. Chest 2006;130:989-94.

36. de Kleijn WP, Elfferich MD, De Vries J, et al. Fatigue in sarcoidosis: American versus Dutch patients. Sarcoidosis Vasc Diffuse Lung Dis 2009;26:92-7.

37. Atkins $C$, Wilson $A M$. Managing fatigue in sarcoidosis - a systematic review of the evidence. Chron Respir Dis 2017:14:161-73.

38. de Kleijn WP, De Vries J, Wijnen PA, et al. Minimal (clinically) important differences for the fatigue assessment scale in sarcoidosis. Respir Med 2011;105:1388-95.

39. Patel AS, Siegert RJ, Creamer D, et al. The development and validation of the King's sarcoidosis questionnaire for the assessment of health status. Thorax 2013;68:57-65.

40. Van Manen MJ, Wapenaar M, Strookappe B, et al. Validation of the King's sarcoidosis questionnaire (KSQ) in a Dutch sarcoidosis population. Sarcoidosis Vasc Diffuse Lung Dis 2016;33:75-82.

41. Baughman RP, Nagai S, Balter M, et al. Defining the clinical outcome status (COS) in sarcoidosis: results of WASOG Task Force. Sarcoidosis Vasc Diffuse Lung Dis 2011;28:56-64.
42. Scadding JG. Prognosis of intrathoracic sarcoidosis in England. A review of 136 cases after five years' observation. Br Med $J$ 1961;2:1165-72.

43. Judson MA, Boan AD, Lackland DT. The clinical course of sarcoidosis: presentation, diagnosis, and treatment in a large white and black cohort in the United States. Sarcoidosis Vasc Diffuse Lung Dis 2012;29:119-27.

44. Judson MA, Chaudhry H, Louis A, et al. The effect of corticosteroids on quality of life in a sarcoidosis clinic: the results of a propensity analysis. Respir Med 2015;109:526-31.

45. Prasse A, Katic C, Germann M, et al. Phenotyping sarcoidosis from a pulmonary perspective. Am J Respir Crit Care Med 2008;177:330-6.

46. Moller DR, Koth LL, Maier LA, et al. Rationale and design of the genomic research in alpha-1 antitrypsin deficiency and sarcoidosis (GRADS) study. Sarcoidosis protocol. Ann Am Thorac Soc 2015;12:1561-71.

47. Mason A, Street A. Publishing outcome data: is it an effective approach? J Eval Clin Pract 2006;12:37-48.

48. Dziuban SW, Mcllduff JB, Miller SJ, et al. How a New York cardiac surgery program uses outcomes data. Ann Thorac Surg 1994;58:1871-6.

49. Davies H. Falling public trust in health services: implications for accountability. J Health Serv Res Policy 1999;4:193-4.

50. Stey AM, Russell MM, Ko CY, et al. Clinical registries and quality measurement in surgery: a systematic review. Surgery 2015;157:381-95.

51. Baughman RP, Barriuso R, Beyer K, et al. Sarcoidosis: patient treatment priorities. ERJ Open Res. In Press 2018;4:001412018-2018.

25. Czerwiński E, Badurski JE, Marcinowska-Suchowierska E, et al. Current understanding of osteoporosis according to the position of the World Health Organization (WHO) and International Osteoporosis Foundation. Ortop Traumatol Rehabil 2007;9:337-56.

53. Judson MA, Costabel U, Drent M, et al. The WASOG sarcoidosis organ assessment instrument: an update of a previous clinical tool. Sarcoidosis Vasc Diffuse Lung Dis 2014;31:19-27. 